\title{
Oxidative polymorphism of debrisoquine in Parkinson's disease
}

J Benitez, J M Ladero, F J Jimenez-Jimenez, C Martinez, A M Puerto, $M$ J Valdivielso, A Llerena, J Cobaleda, J J Muñoz

\begin{abstract}
Oxidative phenotype and metabolic ratio (MR) of debrisoquine (DBQ) have been determined in 87 patients with Parkinson's disease and in 556 healthy control subjects. Three patients $(3 \cdot 45 \%)$ and 34 control subjects $(6 \cdot 12 \%)$, having an $\mathrm{MR}$ $>12 \cdot 6$, were classified as poor metabolisers (PM) of DBQ (ns). The distribution of $M R$ values in the 84 Parkinsonian patients classified as extensive metabolisers (EM) showed a less efficient oxidative rate when compared with controls of the same phenotype $(p<0.001)$. This difference may be due to enzymatic inhibition caused by drug treatment in 40 of these patients. As in patients not taking any drug known to inhibit the oxidation of DBQ, distribution of MR values was not different from that in controls. A negative correlation $(r=-0.36, p<0.02)$ was found between MR of DBQ and age at onset of disease in patients free of drugs known to interact with DBQ metabolism. A higher rate of $D B Q$ oxidation could be a genetic factor that delays the clinical onset of Parkinson's disease in predisposed people.
\end{abstract}

Debrisoquine (DBQ), an adrenergic-blocking drug, is oxidised in the liver to 4-hydroxydebrisoquine (4-OH DBQ) following a polymorphic reaction that depends on the isozyme dbl of the microsomal cytochrome P-450 system (P-450 II D1). ${ }^{1}$ The rate of activity of this isozyme shows a genetic polymorphism: homozygotes for the recessive allele are almost completely unable to 4-hydroxylate $\mathrm{DBQ}$ and are designated poor metabolisers (PM) of $\mathrm{DBQ}$, whereas homo and heterozygotes for the dominant allele hydroxylate DBQ efficiently and are classified as extensive metabolisers (EM). ${ }^{2}$ The biochemical defect in PM might be due either to the synthesis of an abnormal molecule of the isozyme ${ }^{3}$ or, more probably, to the absence of isozyme. ${ }^{4}$ Two mutant alleles associated with this deficiency have been identified, ${ }^{1}$ and the gene controlling the synthesis of this isozyme has been traced to the long arm of chromosome 22.5 Drugs that share the oxidative pathway of DBQ are competitive inhibitors of its metabolism; $; 0-10$ in addition there are other drugs that, although not following this route, may interfere with it. ${ }^{112}$ On the other hand, the activity of the isozyme P-450 dbl is hardly modifiable by some known inducers of the oxidative microsomal system, ${ }^{13}$ and seems not to be influenced by age, sex or tobacco and alcohol consumption. ${ }^{14}$

The cause of Parkinson's disease is unknown. However, genetic predisposition, ageing, and neurotoxicity by chemicals, may all play a role. ${ }^{15}$ Barbeau et al ${ }^{16}$ determined the oxidative polymorphism of DBQ in a group of Parkinsonian patients and stated that "poor metabolisers among PD patients tended to have an earlier age at onset of the disease". Afterwards, the same group ${ }^{17}$ attributed much of that lower oxidative rate to enzymatic blocking caused by the concurrent administration of the antihistamine drugs diphenhydramine or orphenadrine, but concluded that "the observation that non-(poor) metabolisers of debrisoquine tend to have an earlier age of onset and an early severe course of PD still holds true". Comella $e$ e al and Tanner et al ${ }^{18} 19$ detected a non-significant excess of slow metabolisers of DBQ in their patients aged under 40 years at clinical onset.

In this study we have aimed to elucidate the possible relationship between Parkinson's disease and oxidative polymorphism of $\mathrm{DBQ}$, taking particular care to eliminate bias produced by the concomitant use of drugs capable of interfering with its enzymatic activity.

\section{Patients and methods}

The study involved 87 patients (46 male, 41 female, mean age 65.1 years, SD 9.9) with a diagnosis of Parkinson's disease. Informed consent was a prerequisite for inclusion in the study, as indeed was normal gut, liver and kidney function. Data on age at clinical onset of the disease, tobacco and alcohol use and current drug treatment were collected in every case. The clinical staging of the disease was established according to Hoehn and Yahr. ${ }^{20}$

Forty five patients not receiving drugs or only levodopa-carbidopa and/or bromocriptine formed the subgroup A ("untreated"). The remaining 42 patients (subgroup B, "treated"), were receiving one or more of the following drugs known to affect DBQ metabolism: neuroleptics, anticholinergics, tricyclic antidepressants, and beta blocker agents. No patient had received any antihistamine drug, either anti-H1 or anti-H2, in the previous three weeks.

The control group comprised 556 healthy subjects (272 male, 284 female, mean age 25 years, SD 7.3), who were not taking any drug.

The oxidative ratio of $\mathrm{DBQ}$ was determined by giving a $10 \mathrm{mg}$ Declinax tablet at 22.00 hours, (two hours after a light dinner) and 
Figure Cumulative rate of frequencies of $M R$ values in both control and patient groups. Patients in subgroup $A$ and $B$ are, respectively, free and subjected to drug interactions. Subjects with $\log 10 M R>1 \cdot 1(6 \cdot 1 \%$ of the control group, $2 \cdot 2 \%$ of subgroup $A$ and $4.8 \%$ of subgroup $B$ ) are designated poor metabolisers (PM). The remainder are extensive metabolisers (EM).

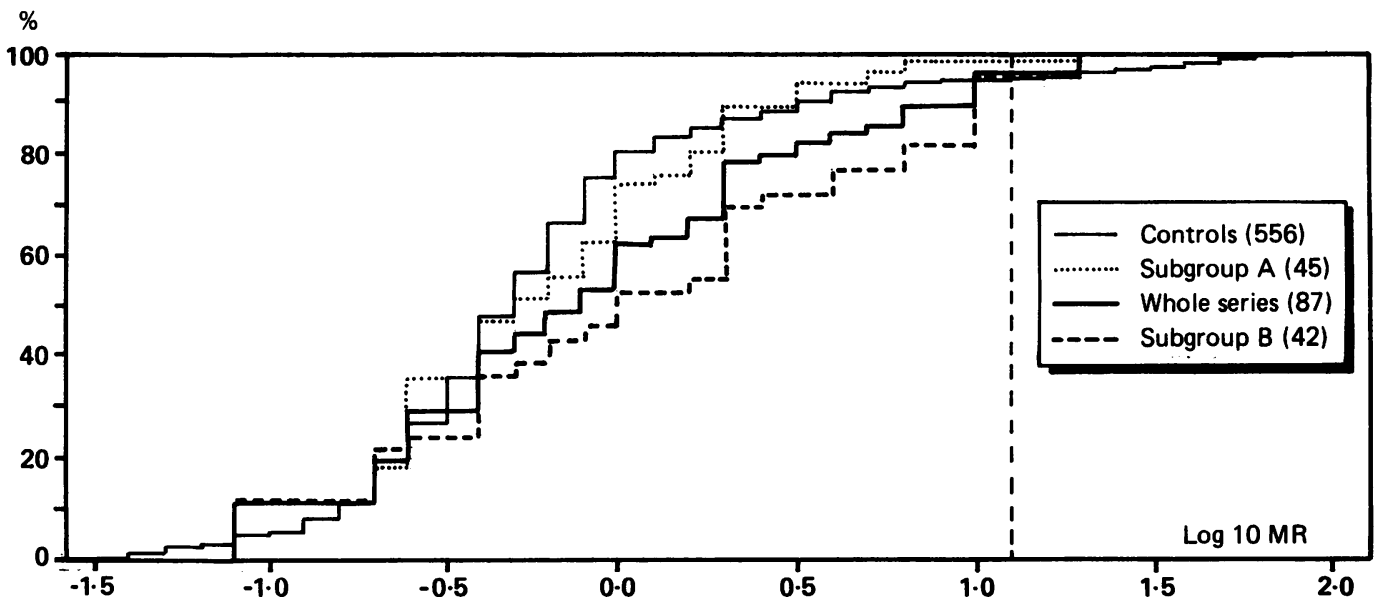

collecting all the urine in the following eight hours. The volume was measured and aliquots were stored at $-20^{\circ} \mathrm{C}$ until analysis.

Measurement of DBQ and of its main metabolite, 4-OH DBQ, in urine was performed using the flame-ionisation gaschromatographic method described by Lennard et al. $^{21}$ Metabolic ratio was calculated according to the formula ${ }^{2}$ :

$\mathrm{MR}=\frac{\% \text { Dose excreted as unchanged DBQ }}{\% \text { Dose excreted as 4-hydroxy DBQ }}$

The limit between poor and extensive metabolisers was established at a value for $M R$ of $12.6(\log 1 \cdot 1)$, proposed by Price-Evans' et $a^{22}$

The statistical analysis was performed using the Chi-squared test with Yates' correction, the nonparametrical Kolmogarov-Smirnov test and the calculation of linear correlation coefficients when appropriate. ${ }^{23}$ The null hypothesis was rejected when $p<0 \cdot 05$.

\section{Results}

Three patients $(3.45 \%)$, one (age of disease onset 24 years) in subgroup $A$ and two (age of disease onset 55 and 78 years respectively) in subgroup $B$, and 34 control subjects $(6 \cdot 12 \%)$ with $M R$ values $>12.6$, were classified as poor metabolisers of $\mathrm{DBQ}$ (Chi squared $=0.99$, not significant).

A separate analysis has been performed in extensive metabolisers (EM) of both patients and control groups. The distribution of MR values of DBQ showed higher values in patients ( $p<0.001)$, reflecting a lower oxidative rate in the whole group of EM

Table Comparative distribution in patients and in controls of (1) oxidative phenotype of $D B Q$ and (2) $M R$ values of extensive metabolisers

\begin{tabular}{|c|c|c|c|c|}
\hline \multirow{3}{*}{$\begin{array}{l}\text { Controls (556) } \\
\text { Patients: } \\
\text { Total series (87) } \\
\text { Subgroup A (45) } \\
\text { Subgroup B (42) }\end{array}$} & \multicolumn{2}{|c|}{$\begin{array}{l}\text { (1) } \\
\text { Extensive } \\
\text { metabolisers }\end{array}$} & \multicolumn{2}{|c|}{$\begin{array}{l}\text { (2) Metabolic } \\
\text { Ratio (MR) } \\
\text { in extensive } \\
\text { metabolisers } \\
\text { Mean (SD) }\end{array}$} \\
\hline & 522 & $(93.88)$ & 0.85 & $(1 \cdot 19)$ \\
\hline & $\begin{array}{l}84 \\
44 \\
40\end{array}$ & $\begin{array}{l}(96 \cdot 55) \\
(97 \cdot 80) \\
(95 \cdot 20)\end{array}$ & $\begin{array}{l}1.91 \\
1.13 \\
2.77\end{array}$ & $\begin{array}{l}(2.92)^{\star} \\
(1.46) \dagger \\
(3.77)^{\star}\end{array}$ \\
\hline
\end{tabular}

patients than in EM controls subjects. This difference persisted at the same level of significance when EM patients of subgroup B ("treated") were compared with controls, but disappeared when EM patients of subgroup A ("untreated") were compared (fig, table).

In the subgroup A ("untreated"), age at onset of the disease and MR values were inversely and significantly related $(\mathrm{r}=-0.36$, $p<0.02$ ). The only PM patient in the subgroup A was a male whose age of disease onset was 24 years. In the other patient in subgroup A with young onset ( $<40$ years) symptoms began at age 33 . In contrast, no correlation with age was found when analysing either subgroup B ("treated") or the whole series.

Clinical stage of the disease was not related to MR values in either the whole series or in subgroups A and B considered separately.

\section{Discussion}

The distribution of the oxidative polymorphism of DBQ in our patients with Parkinson's disease did not differ from that found in the control group. Nevertheless, when analysing separately the distribution of $M R$ of $D B Q$ just in extensive metabolisers, we found a lower oxidative rate in EM patients than in EM controls.

Although mean age is lower in the control group than in patients, ageing does not reduce the oxidative rate of DBQ. ${ }^{14}$

Subgroup A ("untreated") includes both genuinely untreated patients and patients on treatment only with levodopa and/or bromocriptine, which do not interfere with the metabolism of DBQ. ${ }^{10}$ The distribution of $M R$ values in EM patients of subgroup $A$ is not different from that noticed in EM subjects of the control group (fig). However, when comparing the distribution of MR values between EM subjects of the group of patients treated with drugs capable of interfering with dbl P450 isozyme (subgroup B, "treated") and EM control subjects, significantly $(p<0.001)$ higher MR values were detected in patients. This reduction in the oxidative rate of DBQ in these "treated" Parkinsonian patients with the EM phenotype is probably due to the inhibitory effect that some drugs exert on the cytochrome P-450 db1. ${ }^{6-12}$ This finding agrees 
with those of Poirier et al, ${ }^{17}$ that antihistamine drugs affected DBQ metabolism in their patients

After excluding, as far as possible, confounding drug interactions, the main conclusion of our study is that oxidative rate of DBQ and age at onset of Parkinson's disease are inversely correlated. This result supports the theory that a high oxidative rate of DBQ might exert a protective effect against development of disease in predisposed people, by possibly providing a better means of inactivating some chemical(s), endogenous and/or exogenous, hypothetically involved in the neuronal damage that causes the disease.

MPTP (N-methyl-4-phenyl-1,2,3,6-tetrahydropyridine), a contaminant of "synthetic" heroin, can cause a clinical picture very similar to idiopathic Parkinson's disease and has been used to induce diverse experimental models of the illness. Its neurotoxic effect seems to be mediated by its metabolite MPP,$+{ }^{24} 25$ which is formed in situ in the brain by the action of the mitochondrial MAO. ${ }^{26}{ }^{27}$ MPTP is also oxidised in the liver by the $\mathrm{P}-450 \mathrm{dbl}$ isozyme. ${ }^{28} \mathrm{In}$ addition, the existence of $P-450$ cytochromes of families $C$ and $D$ in the rat brain has recently been shown. ${ }^{29}$ The fraction of MPTP that follows the $\mathrm{P}-450$ cytochrome pathway escapes transformation to MPP + and, assuming that the alternative metabolites are not neurotoxic, this enzymatic route should protect against the neurotoxic effects of MPTP. Cytochrome P$450 \mathrm{dbl}$ shows polymorphic activity so that the degree of protection that it might provide should vary as a function of its genetic endowment.

In the environment there are substances structurally related to MPTP that might be involved in the cause of Parkinson's disease, such as some pesticides and herbicides. ${ }^{30-32} \mathrm{~N}$ methyl derivatives of $\beta$-carbolines form a group of endogenous substances with some resemblance to MPTP and hypothetically related to the origin of Parkinson's disease. ${ }^{33-37}$ They also follow the P-450 dbl pathway. ${ }^{10}$

The isozyme P-450 dbl represents only a small part of the whole oxidative capacity of the cytochrome P-450 system. Many other isozymes intervene in the metabolism of endoand xenobiotics, and the rate of activity of some of them is also genetically determined. Data on the activity of these other isozymes in Parkinson's disease ${ }^{38}$ and in other neurological conditions with genetic and environmental causes ${ }^{39}$ are scanty. Nevertheless, their relative importance in the origin of many of such diseases should be fully investigated.

Addendum: Steventon et al ${ }^{40}$ studied 66 patients with untreated idopathic parkinsonism. They found no differences between cases and controls when comparing either the distribution of hydroxylator phenotype of $\mathrm{DBQ}$ or the distribution of $M R$ values for $D B Q$. They concluded that "detoxification by $\mathrm{P}-450-\mathrm{dbl}$ ... appears to be irrelevant to the aetiology of PD”.

This study was supported by grants CYCT
P886-0672, CAICYT P885-0154 and FISS 88/0898.

Dr S Giménez-Roldan and Dr D Mateo gave their consent and full cooperation for this study on their patients at the Parkinson's Clinic of the Service of Neurology, General Gregorio Marañón Hospital, Madrid.

1 Skoda RC, González FJ, Demierre A, Meyer UA. Two mutant alleles of the human cytochrome P-450 dbl gene (P450C2D1) associated with genetically deficient metabolism of debrisoquine and other drugs. Proc Natl Acad Sci USA 1988;85:5240-43.

2 Mahgoub A, Idle JR, Dring LG, Lancaster R, Smith RL. Polymorphic hydroxylation of debrisoquine in man. Lancet 1977;ii:584-6.

3 Osikowska-Evers B, Dayer P, Meyer UA, Robertz GM, Eichelbaum M. Evidence for altered catalytic properties of the cytochrome P-450 involved in sparteine oxidation in of the cytochrome P-450 involved in sparteine oxidation in

poor metabolizers. Clin Pharmacol Ther 1987;41:320-5.
González FJ, Skoda RC, Kimura S, et al. Characterization of the common genetic defect in humans deficient in debrisoquine metabolism. Nature 1988;331:442-6.

5 Eichelbaum M, Baur MP, Dengler HJ, et al. Chromosomal assignment of human cytochrome P-450 (debrisoquine/ sparteine type) to chromosome 22. Br J Clin Pharmacol 1987;23:455-8.

6 Larrey D, Pessayre D, Benhamou J-P. Polymorphisme génétique du métabolisme hépatique des médicaments. Gastroenterol Clin Biol 1985;9:522-31.

7 Roots I, Otte F, Berchtold C, Heinemeyer G, Schmidt D, Cornaggia C. Debrisoquine phenotyping in epileptic patients treated with phenytoin and carbamazepine. patients treated with phenytoin
Biochem Pharmacol 1985;34:447-8.

8 Bechtel P, Joanne C, Bechtel Y, Grandmottet M, Jounet JM. Stabilité et/ou variabilité de l'expression du polymorphisme génétique d'hydroxylation et d'acetylation chez les malades présentant des pathologies et soumis à des thérapeutiques variées. Ann Biol Clin 1986;44:361-7.

9 Syvälahti EKG, Lindberg R, Kallio J, de Vocht $M$ Inhibitory effects of neuroleptics on debrisoquine oxidation in man. Br J Clin Pharmacol 1986;22:89-92.

10 Fonne-Pfister R, Meyer UA. Xenobiotic and endobiotic inhibitors of cytochrome P-450 dbl function, the target of the debrisoquine/sparteine type polymorphism. Biochem Pharmacol 1988;37:3829-35.

11 Brosen K, Gram LF, Haghfelt T, Bertilsson L. Extensive metabolizers of debrisoquine become poor metabolizers during quinidine treatment. Pharmacol Toxicol 1987;60: during

12 Steiner E, Spina E. Differences in the inhibitory effect of cimetidine on desimipramine metabolism between rapid and slow debriso

13 Eichelbaum M, Mineshita S, Ohnhaus EE, Zekorn C. The influence of enzyme induction on polymorphic sparteine oxidation. Br J Clin Pharmacol 1986;22:49-53.

14 Steiner E, Iselius L, Alván G, Lindsten J, Sjöqvist F. A family study of genetic and environmental factors determining polymorphic hydroxylation of debrisoquin. Clin Pharmacol Ther 1985;38:394-401.

15 Calne DB, Langston JW. Aetiology of Parkinson's disease. Lancet 1983;ii: 1457-75.

16 Barbeau A, Cloutier T, Roy M, Plasse L, Paris S, Poirier J. Ecogenetics of Parkinson's disease: 4-hydroxylation of debrisoquine. Lancet 1985;ii:1213-6.

17 Poirier J, Roy M, Campanella G, Cloutier T, Paris S. Debrisoquine metabolism in parkinsonian patients treated with antihistamine drugs. Lancet 1987;ii:386.

18 Comella CL, Tanner CM, Goetz CG, Gans S, Rapp D, Fischer J. Debrisoquine metabolism in Parkinson' disease. Neurology 1987;37(suppl 1):261-2.

19 Tanner CM, Chen B, Wang WZ, et al. Environmental factors in the etiology of Parkinson's disease. Can J Neurol Sci 1987;14(Suppl 3):419-23.

20 Hoehn MM, Yahr MD. Parkinsonism: onset, progression and mortality. Neurology 1967;17:427-42.

21 Lennard MS, Silas JH, Smith AJ, Tucker GT. Determination of debrisoquine and its 4-hydroxy metabolite in biological fluids by gas chromatography with flame ionization and nitrogen-selective detection. $J$ Chromatograph 1977;133:161-6.

22 Evans DAP, Mahgoub A, Sloan TP, Idle JR, Smith RL. A family and population study of the genetic polymorphism of debrisoquine in a white British population. J Med Genet of debrisoquine in

23 Carrasco JL. Ei método estadístico en la Investigación médica. Madrid: Editorial Ciencia 3, 1986.

24 Markey SP, Johanneseen JN, Chiueh CC, Burns RS Herkenham MA. Intraneuronal generation of a pyridinium metabolite may cause drug-induced parkinsonism. Nature 1984;311:464-7.

25 Langston JW, Irwin I, Langston EB, Forno LS. 1-methyl4-phenylpyridinium ion (MPP + ): identification of a metabolite of MPTP, a toxin selective to the substantia nigra. Neurosci Lett 1984;48:87-92. 
26 Chiba K, Trevor A, Castagnoli N. Metabolism of the neurotoxic tertiary amine, MPTP, by brain monoamine rain monoamine

27 Heikkila RE, Manzino L, Cabbat FS, Duvoisin RC. Studies on the oxidation of the dopaminergic neurotoxin 1methyl-4-phenyl-1,2,3,6-tetrahydropyridine by monomethyl-4-phenyl-1,2,3,6-tetrahydropyridine by

28 Fonne-Pfister R, Bargetzi MJ, Meyer UA. MPTP, the neurotoxin inducing Parkinson's disease, is a potent competitive inhibitor of human and rat cytochrome $P 450$ isozymes (P450buf-I, P450db1) catalyzing debrisoquine 4-hydroxylation. Biochem Biophys Res Commun 1987;148: $1144-50$.

29 Köhler C, Eriksson LG, Hanson T, Warner M, AkeGustafsson J. Immunohistochemical localization of cytochrome P450 in the rat brain. Neurosci Lett 1988;84: 109-14.

30 Barbeau A, Roy M. Genetic susceptibility, environmental factors and Parkinson's disease. Proceedings of the VIII International Symposium on Parkinson's disease. June International Symposium on

31 Barbeau A, Roy M, Cloutier T, Plasse L, Paris S. Environmental and genetic factors in the etiology of Parkinson's disease. Adv Neurol 1986;45:299-306.

32 Bocchetta A, Corsini GU. Parkinson's disease and pesticides. Lancet 1986;ii: 1163.

33 Ohkubo S, Hirano T, Oka K. Methyltetrahydro- $\beta$-carbolines and Parkinson's disease. Lancet 1985;ii:1272-3.
34 Collins MA, Neafsey ERJ. $\beta$-carboline analogues of $\mathrm{N}$ methyl-4-phenyl-1,2,3,6-tetrahydropyridines (MPTP) endogenous factors underlying idiopathic parkinsonism? Neurosci Lett 1985;55:179-84.

35 Ung-Chhun N, Neafsey EJ, Collins MA. 2-methyl-tetrahydro- $\beta$-carboline, a potential endogenous "MPTP-like" hydro- $\beta$-carboline, a potential endogenous "MPTP-like" agent: striatal

36 Testa B, Naylor R, Costall B, Jenner P, Marsden CD. Does an endogenous methylpyridinium analogue cause Parkinson's disease? J Pharm Pharmacol 1985;37:679-80.

37 Collins MA, Neafsey EJ, Cheng BY, et al. Endogenous analogs of N-methyl-4-phenyl-tetrahydropyridine (MPTP): indoleamine derived tetrahydro- $\beta$-carbolines as potential causative factors in Parkinson's disease. Adv Neurol 1986;45:179-82.

38 Factor SA, Hefti F, Weiner WJ. Acetaminophen metabolism by cytochrome P-450 in Parkinson's disease. In: Shoulson I, Fahn S, Langton JW. Symposium on the etiology, pathogenesis, and prevention of Parkinson's etiology, pathogenesis, and preven
disease. Arch Neurol 1988;45:807-11.

39 Steventon G, Williams AC, Waring RH, Pall HS, Adams D. Xenobiotic metabolism in motorneuron disease. Lancet 1988;ii:644-7.

40 Steventon GB, Heafield MTE, Sturman SG, Waring RH Williams AC, Ellingham J. Degenerative neurological disease and debrisoquine-4-hydroxylation capacity. Med Sci Res 1989;17:163-4. 